\title{
Role of Gastric Lavage in Management of Ingested Poisoning-A Review
}

\author{
Dr. Jyoti Mane', Dr. Veena Patil ${ }^{2}$ \\ ${ }^{1}$ M.D., Agadtantra \\ ${ }^{2}$ M.D. Phd-Streerog Prasutitantra
}

\begin{abstract}
The management of the poisoning patient is an emergency procedure. In many of the hospitals the attending physician recommends gastric lavage as the patient is brought in. Gastric lavage is the procedure which is carried out routinely to clean the stomach contents i.e. elimination of the poison which is not being absorbed as well as to prevent reabsorbtion of the same. It should be carried out with great care and precaution to overcome morbidity and mortality. This procedure is carried out in case of ingested poisons ie. the poisoning through oral route. The attending physician should be able to decide whether the patient is fit for the procedure before carrying out the process. This process should be carried out in time, in proper patient and following the precautions for the beneficial effect of the process.
\end{abstract}

Keywords: Gastric lavage, ingested poison, Ewalds tube

\section{Introduction}

During management of the poisoning patient with the history of ingestion of the poison [1], the procedure which is routinely carried out is Gastric lavage commonly known as stomach wash, stomach pumping, and Gastric irrigation [2]. It is one of the processes used to clean the stomach contents.[5] This is the process carried out since ancient period to remove the unabsorbed poison from the body.[3] It is also used to administer antidote for the left over poison in the stomach.[4] It is the procedure recommended to be carried out within 3 hours of ingestion of poison and in some exceptional cases like salicylic acid , trigyclic, carbamazepine and barbiturate toxicity it is advised to carry out up to 6 to 12 hours of ingestion[2].

\section{Aim and Objectives}

1) To make the society aware of benefits of gastric lavage in managing the poisoned, if attended as early as possible.

2) To give maximum information regarding the procedure which is not possible during the procedure as it's an emergency management.

\section{Material and Methods}

The instrument used to carry out this procedure is known as Ewald tube or Boas tube, in case of its non availability ordinary rubber tube of 1 centimetre diameter and 1 and $1 / 2$ meter length can be used [5]. One end of the tube is blunt and another end has a funnel, it has a suction bulb to pump the stomach contents [5]. It is now replaced by disposable gastric lavage kits available in markets.

\section{Procedure}

The recommended position for carrying procedure is prone or semi prone especially towards left side [2]. The position of the mouth should be lowered than that of larynx which is achieved by giving the hanging position to the head well known medically as trendelburg and left lateral decubitus position [2]. After the proper recommended position the tube is first lubricated with oil or glycerine or xylocaine jelly and passed through the opening present in the middle of the mouth gag into the stomach by depressing the tongue with tongue depressor and then slowly passing through pharynx and oesophagus till it reaches the stomach. [5]. The estimated length from teeth to the first part of the stomach ie. Cardiac end of the stomach is about $50 \mathrm{cms}$ [5]. The tube is inserted with great care and precaution to overcome secondary complications viz.injury, perforation [4].

After proper insertion of the tube in the stomach its position is to be confirmed by dipping the funnel end in water, if the position of the tube is in air passage then presence of air bubbles are noticed at the funnel end [5]. After confirmation of the position plain water approximately $500 \mathrm{ml}$ is run into the funnel, the position of the funnel should be above the level of the patients mouth.[5] Due to gravity the fluid enters the stomach, after few minutes the position of the stomach is lowered to bring back the water (gastric contents) [1] . This particular first wash is to be preserved and sent to chemical analysis [5]. Common salt is added to the first wash obtained, as a preservative before sending it to the analysis. The same process is being repeated with lukewarm water or salt water or the solution containing appropriate antidote, till the returning fluid do change its colour [1].

To prevent reabsorbtion of the poison which can be later excreted in the stomach or the poison which might have escaped stomach wash procedure, a solution containing antidote is left behind in the stomach, later this is eliminated out through excretion with the help of magnesium sulphate or sodium sulphate [1]

After completing all the steps the stomach wash tube is withdrawn with great care ie. by pinching the free end of the tube preventing aspiration of the fluid into the lungs[5].

In case of children this procedure is carried out with a narrower calibre and short length tube. Ryle's tube or 


\section{International Journal of Science and Research (IJSR) \\ ISSN (Online): 2319-7064 \\ Index Copernicus Value (2015): 78.96 | Impact Factor (2015): 6.391}

French rubber catheter of 8 to 12 size is preferred for the same, all othe procedure is same as adult [5].

\section{Contraindication [1]}

Gastric lavage is not recommended in patient's Haemorrhagic diathesis, oesophageal varices, recent surgery, advanced pregnancy, ingestion of alkali and coma.

It is again strictly contraindicated in hypothermia, prior significant vomiting, in case of coma when the airway is unprotected, ingestion of acid, convulsions, petroleum distillate toxicity and ingestion of sharp foreign body[1].

\section{Complications [1]}

1) Pneumonia due to aspiration

2) Laryngo spasm

3) ST elevation on ECG and sinus brady cardia

4) Gastric perforation or oesophagus (rare)

\section{Conclusion and Result}

It is clear that this procedure is carried out to remove the poison from the body prior to its digestion and its absorbtion. It is carried out only in case of ingested poison especially when ingested in fatal dose. This procedure is not only used to remove the unabsorbed poison but also during resuscitation in new born, to relive the newborn from the adverse effect of meconium or the amniotic fluid aspirated during the process of labour

\section{References}

[1] Modern medical Toxicology- V.V.Pillay- page no 19\&20 fourth edition 2013, Jaypee brother's medical publisher's ltd.

[2] Text book of forensic medicine and toxicology-Krishnan vij-page no. $450 \& 451$ fifth edition 2012, Elsevier publication

[3] Cooling techniques for hyperthermia: treatment and medication e medicine. Omaha

[4] American academy of clinical toxicology; European association of poisons centres and clinical toxicologists.

[5] Text book of medical jurisprudence, forensic medicine and toxicology- Dr.C.K.Parikh-page no. $-8.13 \& 8.14$, Sixth edition 2006, CBS publishers.

\section{Author Profile}

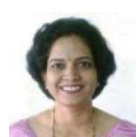

Dr.Jyoti Chandrashekhar Mane, completed graduation in Ayurved (B.A.M.S.) from Gulburga University,Karnataka and postgraduation (M.D.) in the subject of Agadtantra from Bharti Vidhyapeeth Pune, Maharashtra. She is presently working as Assistant Professor in the Department of Agadtantra at Dr.J.J.Magdum Ayu.Medical College, Jaysingpur.with 5 years of Teaching Experience.

Dr.Veena Patil, completed graduation in Ayurved(B.A.M.S) from Maharashtra University of Health Sciences, Maharashtra and Post Graduation (M.D.) in the subject of Streerog evum prasutitantra from Maharashtra university of Health Sciences, Maharashtra.and doctorate (P.hd)from Tilak Maharashtra Vidhyapeeth Pune. Presently she is working as professor in the department of Streerog and prasutitantra at Government Ayurved Medical College, Usmanabad with 15 years of teaching experience. 